\title{
Da Evidência ao Gut feelings
}

Raquel Braga*

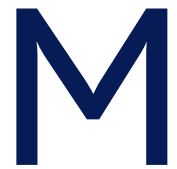
uito se fala actualmente de Medicina Baseada na Evidência (MBE) e muitos são os que procuram nas melhores fontes de informação as mais actualizadas e mais credíveis provas científicas para apoiar a resposta clínica a dar ao paciente em cada situação.

A necessidade de praticar uma MBE em vez daquilo que, com uma pontinha de picardia, poderíamos denominar de MBO (Medicina baseada na opinião) já começou há algum tempo, paulatinamente, a fazer parte do nosso dia-a-dia clínico e a estar entranhada no nosso modus operandi. Já não é sem tempo, uma vez que a génese filosófica desta corrente teve início em meados do século XIX... ${ }^{1}$

No entanto, no momento de interpretar as evidências ou de graduar as provas científicas usando as escalas de evidências, muitas são as dúvidas e as inseguranças.

Vejamos o que se passa na saudável e importante discussão levantada pela carta ao Director ${ }^{2}$ e respectiva resposta ${ }^{3}$ publicadas nesta edição a propósito de um artigo do Dossier «Adolescência» publicado num número anterior da Revista Portuguesa de Clínica Geral. ${ }^{4}$

Um procedimento recomendado no artigo «Boletim de saúde Infantil e Juvenil - o exame global de saúde dos 11 aos 13 anos (parte II)»", a execução da manobra de Adams na consulta do exame global de saúde dos 11-13 anos, foi posto em causa, à luz do que é recomendado pela USPSTF (United States Preventive Services Task For$c e$ ), que analisa o rastreio da escoliose idiopática enquanto rastreio comunitário. ${ }^{4}$ Segundo a USPSTF, a avaliação do custo-benefício do rastreio comunitário da escoliose no adolescente não demonstra benefícios, porque mesmo detectando casos de alterações, não resultam ganhos em saúde das intervenções até aqui propostas como tratamento (exercícios ou uso de coletes). Estes tratamentos médicos aparentemente não alteram o curso da maior parte das escolioses idiopáti-

*Directora da Revista Portuguesa de Clínica Geral cas detectadas no âmbito de rastreios comunitários analisados pela USPSTF. ${ }^{5}$ A mesma recomendação estabelece que o médico deve estar apto a diagnosticar os casos graves (passíveis de indicação cirúrgica) e a tranquilizar os pais, nos casos que não devem merecer interferência. Infere-se desta recomendação que, no contexto da consulta, é importante saber efectuar o exame e executá-lo sempre que necessário para acautelar estas duas situações. ${ }^{5}$

Devemos estar preparados para saber que as recomendações efectuadas pela USPSTF devem ser lidas no contexto americano, um contexto diferente do nosso, em que o rastreio da escoliose é analisado como rastreio comunitário e que a sua aplicabilidade à nossa realidade pode não ser automática (ou, atrevo-me a dizer, aplicável ao âmbito da nossa consulta). Devemos ter em conta que a escala utilizada pela USPSTF não considera as preferências do paciente ou determinados aspectos de custo-efectividade dos serviços. ${ }^{5,6}$

No seio das actividades preventivas há muitos procedimentos que, apesar de não serem recomendados por rastreio, não perdem o valor de auxiliarem o diagnóstico e muitos outros que, apesar de estarem instituídos pela prática clínica, têm uma indicação duvidosa.

O nosso entusiasmo por querer usar a melhor evidência disponível não pode descansar-nos de a saber ler, interpretar, criticar e aplicar devidamente.

David Sackett, pai da MBE (re)definiu-a na década de 90 como a «aplicação cuidadosa, clara e criteriosa da melhor evidência disponível ao paciente individual.... ${ }^{1}$

Quer isto dizer que, quando avaliamos um paciente e formulamos uma pergunta, na devolução da resposta temos sempre de ter em conta não só a melhor evidência encontrada (leia-se melhor prova científica), mas também a nossa experiência clínica, os valores dos pacientes e as suas circunstâncias únicas. ${ }^{1}$ Todos os lados deste quadrilátero interferem na resposta a dar ao doente.

Significa que, na sua génese e definição, a MBE não conta apenas com a melhor prova científica para dar resposta ao doente. Conta com o médico e com toda a 
sua experiência, sentido clínico e gut feelings. Conta com o doente, com os seus valores, as suas expectativas, as suas crenças e o seu contexto biopsicossocial.

Sabemos que, particularmente numa área tão generalista como a Medicina Geral e Familiar, o domínio do conhecimento científico é determinante para a segurança, solidez e actualização da resposta a dar.

A correcta interpretação do valor de determinada prova científica e da sua aplicabilidade ao nosso doente faz toda a diferença na qualidade da clínica que praticamos.

Sendo uma adepta da MBE, sou também uma adepta do enaltecimento do sentido clínico, daquilo que não constituindo "prova científica» por ser experiência pessoal, limitada no número e na variabilidade dos casos, nos vai marcando como médicos e modelando as nossas repostas clínicas, favorecendo as nossas respostas intuitivas.

Reconheço o valor da intuição que faz despertar campainhas de alarme perante um paciente que, contra todas as probabilidades de uma história aparentemente inofensiva, nos deixa reservas e preocupação, ou da intuição que nos tranquiliza ao tomarmos decisões clínicas inesperadamente contemporizadoras em doentes com histórias aparentemente complicadas. ${ }^{\text {? }}$

Sou portanto, uma crente da "Evidência Nível IV" apresentada por Alison M. Stuebe no seu Perspective de Julho de 2011 no New England, ${ }^{8}$ o nível de evidência que nasce do caso exemplar que nos marcou e que nos faz antecipar futuras decisões clínicas. Sinto-me confortável, aplacada e curiosa pelas correntes científicas que estudam o gut feelings... ${ }^{7}$

Torna-se relevante que o gut feelings (que podemos traduzir como intuição clínica) seja introduzido no nosso pensamento, no nosso ensino e que seja mais bem estudado e objectivado.

Aliás, como a interpretação das evidências, que tem de ser feita cuidadosamente - sem radicalismos apressados e generalistas e já agora com bom senso... clínico.

\section{REFERÊNCIAS BIBLIOGRÁFICAS}

1. Sackett DL, Rosenberg WM, Gray JA, Haynes RB, Richardson WS. Evidence based medicine: what it is and what it isn't. BMJ 1996 Jan 13; 312 (7023): 71-2.

2. Machado N. Rastreio de escoliose no adolescente [carta ao Director]. Rev Port Clin Geral 2011 Jul-Ago; 27 (4): 397.

3. Fonseca H. Resposta à carta ao Director. Rev Port Clin Geral 2011 JulAgo; 27 (4): 397.

4. Freitas $\mathrm{C}$, Sousa $\mathrm{H}$, Fonseca $\mathrm{H}$. Boletim de Saúde Infantil e Juvenil - $\mathrm{o}$ exame global de saúde dos 11 aos 13 anos (parte II). Rev Port Clin Geral 2011; 27 (2): 193-202.

5. Screening for Idiopathic Scoliosis in Adolescents. Recommendation Statement. Disponível em: http://www.uspreventiveservicestaskforce.org/3rduspstf/scoliosis/scoliors.htm [acedido em 21/07/20111].

6. Petitti DB, Teutsch SM, Barton MB, Sawaya GF, Ockene JK, DeWitt T. Comparing the USPSTF and GRADE approaches to recommendations. An Intern Med 2009 Sep 1; 151 (5): 363-4.

7. Stolper $E$, Van de Wiel M, Van Royen P, Van Bokhoven M, Van der Weijen T, Dinant GJ. Gut feelings as a third track in general practitioners' diagnostic reasoning. J Gen Intern Med 2011 Feb; 26 (2): 197-203.

8. Stuebe AM. Level IV evidence: adverse anecdote and clinical practice. N Engl J Med 2011 Jul 7; 365 (1): 8-9.

\section{ENDEREÇO PARA CORRESPONDÊNCIA}

director@rpcg.apmcg.pt 